\title{
EPIDEMIOLOGY OF DIABETES MELLITUS IN BULGARIA
}

\author{
Lidia Koeva and Dmgomir Koev \\ Clinic of Endocrinology, Medical University of Varna, Varna, Bulgaria, \\ Clinical Center of Endocrinology and Gerontology, Sofia, Bulgaria
}

\section{SUMMARY}

- The prevalence of diabetes mellitus in Bulgaria was assessed in 1990 and 1993 by gathering information from a country-wide public health care system. A constant increase of prevalence rate was established beginning from $0.19 \%$ in 1963 to $1.61 \%$ in 1990 and reaching $1.71 \%$ in 1993. Higher prevalence rate was registered in central districts of the country, while in peripheral districts with insufficient specialized diabetological health care it was reported to be unusually low, under $1.0 \%$. Differences in the districts are probably due to insufficient early detection, hidden prevalence and poor registration. Information about diabetic complications was gathered in 1990 and 1994. Prevalence rate of diabetic complications in Bulgaria was comparable with that in other European countries. National Diabetes Care Programme from 1987 and implementation of Saint Vincent Declaration since 1989 resulted in a decrease of proliferative retinopathy from $3.3 \%$ in 1990 to $2.9 \%$ in 1994, blindness due to diabetes from $0.87 \%$ to $0.37 \%$, total number of amputations from $1.90 \%$ to $0.64 \%$ and amputations above the ankle from $0.13 \%$ to $0.04 \%$, respectively. Mortality due to diabetes mellitus was increasing constantly from 8.59/100 000 population in 1973 to 18.95/ 100 000population in 1993. However, in the last seven years, mortality rate increased more slightly with a tendency to reach a plateau level in the next several years - around 19.0/100
000. This might be due to increased efforts in the struggle with diabetes mellitus of the health care providers, diabetologists and lay persons organizations.

\section{IHTBODUCTIOH}

- The prevalence of diabetes mellitus in Bulgaria is followed-up periodically since 1963 . Nevertheless, the publications in this field are scarce and not widely known $(1,2)$. The sources for epidemiological data were mainly the local registers of diabetic patients run by the national health care system. In spite of the fact that registration of diabetes mellitus is compulsory in this country, one may suggest a significant hidden prevalence of diabetes mellitus.

\section{EPIDEMIOLOGY OF DIABETES MELLITUS IN EUROPE AND OTHER COUNTRIES}

- Recently, a trend towards permanent incidence rate increase of diabetes mellitus in Europe and other countries was noted. It is possibly related with considerable improvement of the diagnostic procedures and screening methodology. Overall prevalence rate of diagnosed non-insulin dependent diabetes mellitus (NIDDM) in Italy was $8.5 \%$ in males and $7.9 \%$ in females over the age of 44 years; previously undiagnosed diabetes was $2.5 \%$ in males and $3.4 \%$ in females (3). In Switzer- 
land, the incidence of insulin dependent diabetes mellitus (IDDM) was 4.5/100 000/year in the age cohorts 1948-1950 and 7.2 in the age cohorts 1970-1972. In men between 20 and 40, the age-specific incidence of IDDM up to the age of 43 was approximately 7.0/100 000/year (4). In Romania, the overall annual incidence of IDDM for all ages was 5.7/100 000, the lowest $(1.3 / 100000)$ in the age group $0-4$ years and the highest 10.1/100 000 in the age group 65-69 years; that of NTDDM was 76.3/100 000, the lowest $(2.4 / 100000)$ in the age group 20-24 years and the highest $(261.4 / 100000)$ in the age group 60-64 years (5). The ascertainment-adjusted annual incidence rate was 13.2/100 000 for 0-19-year-old children, indicating an increase of 23\% compared with the 1978-1980 survey; for 0-14-year olds, the increase amounted to $17 \%$ (6). The overall IDDM incidence rate was 8.1/100 000/year in the region of Marche but 30.2/100 000/year in Sardinnia, Italy $(7,8), 7.6 / 100$ 000/year in France (9), 2.5/100 000/year in Macedonia (10), 7.8/100 000/year in the non-Estonian population of Estonia, 4.7/100 000/year in the district of Novosibirsk, Russia (11), while in children under 16 years, it ranged from around 30/100 000/year in Finland and other Northern European countries to less than 1/100 000/year in Japan (12).

Compared with other European countries the prevalence of both IDDM and NTDDM in Bulgaria was constantly lower during the last 30 years (13-16).The incidence of IDDM in children was $6.7 / 100000$ population $(1,17)$. The overall prevalence of both IDDM and NTDDM was always below $2.0 \%$ of the population, even in the last years $(15,18)$. Until now there were no data on the prevalence of the major diabetic complications in Bulgaria because of the lack of a national register and special surveys on diabetic complications.

The aim of this review is to reveal the trends in the prevalence of diagnosed diabetes mellitus and its major complications through information from the local diabetologists in Bulgaria.

\section{PREVALENCE RATE OF DIABETES MELLITUS}

Here we collect the data for the number of all known diabetic patients and their complications in this country and compare the previous data with the present status. Thus, it is possible to outline the trends of these parameters for the near future in order to determine directions for medical action. Concerted actions for improvement of diabetes management and care in the whole country are possible since Bulgaria's public health care system covers all the territory of the country, private medical care is not developed yet, diabetic patients are compulsory registered by local endocrinologists or general practitioners, and patients are under dispensary control.

The data were collected by filling-up unified forms by all doc- tors caring for diabetic patients in 1990 and 1993. The number of registered patients by local doctors is very likely to be close to the real prevalence rate of the disease because all kinds of insulins, all injection devices including insulin pens, all oral drugs and self-control tools (glucometers and strips) are free of charge and all patients are supplied through their local doctors where they are registered. So, all patients are interested to be registered locally. At the time of gathering this information, the number of local diabetes consulting rooms (out-patient clinics) was 72 with 142 diabetologists working there, and general practitioners dealing with diabetic patients were 1647. Information was gathered for all 28 districts of the country with 246 municipalities having total population of 8 989165 in 1990 and of 8549052 in 1993.

For the evaluation of diabetic complications, another unified form was prepared. It was sent to local doctors agreed to participate in the study in 1990. Excluding insufficiently filled forms with missing data of the patients and their complications, forms of 76066 patients were processed from whom complete and reliable data on complications were available. All these patients were on a dispensary control run by endocrinologists or general practitioners.

In order to see the dynamics and trends in the prevalence of diabetic complications in the country we performed a second survey in 1994. We gathered information from all diabetic centers in the country (Table 1), using Basic Information Sheet (BIS) of DiabCare European Information System (19). We succeeded to gather individual forms (BIS) for 3226 patients.

Mortality assessment was done by using mortality records received by National Health Statistic System. Dead diabetic patients were identified on the ground of mentioned diagnosis Diabetes Mellitus either as a cause of death (diabetic coma, hypoglycaemic coma etc) or an underlying and concomitant disease.

Table 1. Centers participating in diabetic complications survey (1994) in Bulgaria

Towns/centers

\begin{tabular}{ll}
\hline Blagoevgrad & Pleven \\
Dobrich & Plovdiv \\
Sofia I & Varna \\
Sofia II & Veliko Tarnovo \\
Sofia III & Vidin \\
\hline
\end{tabular}


Results of categoric variables are reported as percentage with $95 \%$ confidence interval.

The total prevalence rate of diabetes mellitus in Bulgaria in 1990 was 1.61\%: 144725 registered patients out of 8989165 population in the country. During the next several years, the population of Bulgaria decreased significantly due to emigration because of severe economic crisis. In 1993, the prevalence rate increased to $1.78 \%$ : 145333 registered patients out of 8549002 population in the country (Fig.l), the increase of prevalence due predominantly to new-recognized diabetic patients but not to differences in age structure of the population.

Nevertheless, the map of distribution of diabetes mellitus in different districts of the country showed a higher prevalence in the central regions with more dense set of medical institutions and particularly more endocrinologists. In peripheral districts where mainly general practitioners and less qualified doctors work, the estimated prevalence of diabetes mellitus is under $1.5 \%$ (Fig.2). This points out for insufficient early

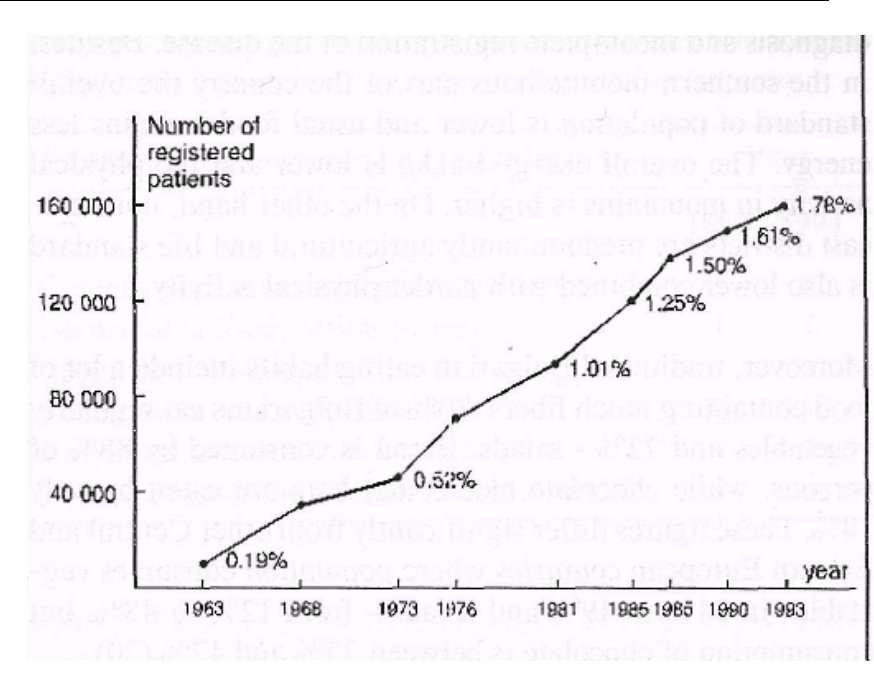

Figure 1. Prevalence rate of diabetes mellitus in Bulgaria.

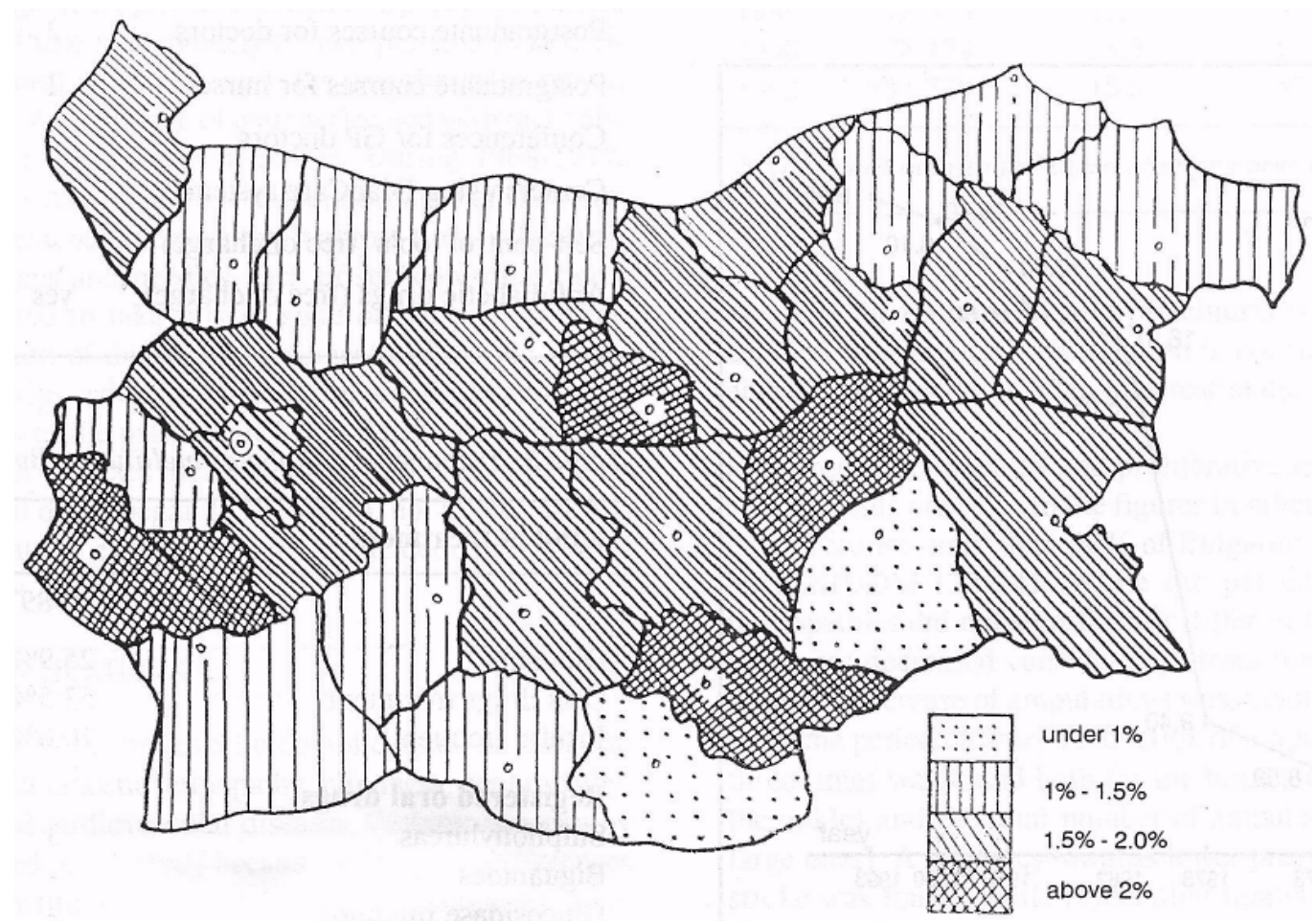

Figure 2. Prevalence rate of diabetes mellitus (1993) in different districts in Bulgaria. 
diagnosis and incomplete registration of the disease. Besides, in the southern mountainous part of the country the overall standard of population is lower and usual food contains less energy. The overall energy intake is lower and the physical activity in mountains is higher. On the other hand, northerneast districts are predominantly agricultural and life standard is also lower combined with harder physical activity.

Moreover, traditional Bulgarian eating habits include a lot of food containing much libers: $80 \%$ of Bulgarians eat regularly vegetables and $72 \%$ - salads. Bread is consumed by $88 \%$ of persons, while chocolate blocks and bars are eaten by only $18 \%$. These figures differ significantly from other Central and Eastern European countries where population consumes vegetables in $34 \%$ to $49 \%$ and salads - from $12 \%$ to $48 \%$, but consumption of chocolate is between $33 \%$ and $47 \%$ (20).

Mortality due to diabetes mellitus was increasing constantly since 1973 , when it was only $8.59 / 100000$ population. The increase was very steeply until 1982 (Fig.3). During 1980s, a lot of measures for better diabetes care in the country were undertaken by the Ministry of Health. A National-wide Programme for struggle with diabetes mellitus was adopted by the Medical Academy and the Ministry of Health. It was

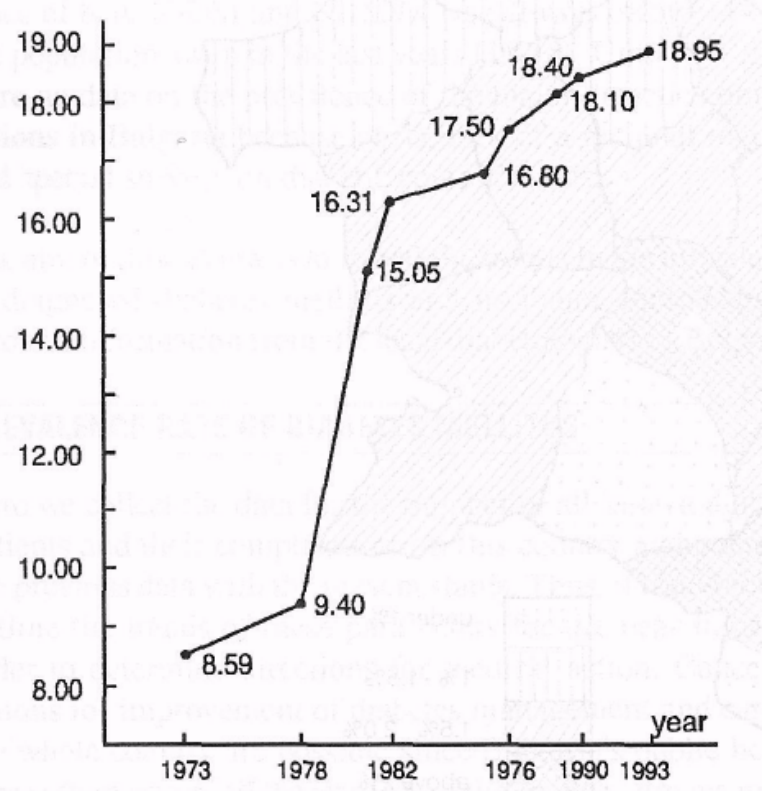

Figure 3. Mortality rate per 100000 population due to diabetes mellitus in Bulgaria. presented at the First Joint Meeting of WHO and IDF in Saint Vincent (Aosta), Italy, 1989 dedicated and entitled Diabetes Care and Research in Europe. The adoption of Saint Vincent Declaration and its implementation in Bulgaria strengthened and accelerated the effective actions for better diabetes health care and treatment (Table 2). Lay persons organizations were founded, self-control at home was widely introduced, human insulins were imported and became available, new oral drugs were registered (Table 3). Patient education started in larger

Table 2. Structural and proffesional health care changes in Bulgaria before and after Saint Vincent Declaration

\begin{tabular}{lcc}
\hline Administrative measures & \multicolumn{2}{c}{ Year } \\
\hline & 1989 & 1994 \\
National programme for diabetes & yes & yes \\
Diabetic out-patient clinic & 66 & 78 \\
Licenced diabetologists in the & & \\
$\quad$ regional hospitals & 142 & 198 \\
Specilized Diabetic Centers & 1 & 2 \\
Diabetic in-patient day-time clinics & 1 & 3 \\
Postgraduate courses for doctors & 2 & 3 \\
Postgraduate courses for nurses & 1 & 3 \\
Conferences for GP doctors & 3 & 6 \\
Centers using DiabCare system & - & 6 \\
Self-control tools (free of charge) & - & yes \\
Antidiabetic drugs (free of charge) & yes & yes
\end{tabular}

Table 3. Treatment of diabetes mellitus in Bulgaria

\begin{tabular}{lcc}
\hline Kind of treatment & \multicolumn{2}{c}{ Year } \\
\hline & 1989 & 1994 \\
Diet only & $25.9 \%$ & $18.6 \%$ \\
Oral drugs treatment & $53.5 \%$ & $58.1 \%$ \\
Insulin tretment & $20.6 \%$ & $23.3 \%$ \\
Registered oral drugs & & \\
Sulphonylureas & 3 & 3 \\
Biguanides & - & 1 \\
Glucosidase inhibitors & - & 1 \\
Insulin preparations & & \\
Conventional insulins & $72 \%$ & $19 \%$ \\
Monocomponent insulins & $23 \%$ & $50 \%$ \\
Human insulins & $5 \%$ & $31 \%$ \\
\hline
\end{tabular}


hospitals, postgraduate education on diabetology for endocrinologists, general practitioners and nurses enlarged (Table 4). Perhaps, these measures reflected on the mortality curve afterwards. The slope of the curve in the last seven years appears to be more smooth down with a tendency to reach a plateau level at around 19.0/100 000 population in the next several years (Fig.2).

\section{TREATMENT OF DIABETES MELLITUS}

Treatment of diabetes mellitus in Bulgaria is not limited by economical restrictions in the country and financial possibilities of the patient because it is guaranteed and paid by the Government. The kind of the treatment is entirely dependent on the doctor's decision. During the last 25 years one may note a constant trend towards an increase in the count of patients treated with insulin, reaching $23.30 \%$ of all patients, including combined insulin and oral drugs treatment.

The percentage of patients treated with diet only was higher in previous years, except 1968 when their registration was probably not complete. Since 1981, there was a constant trend towards a decrease of this category of patients, reaching down to $18.56 \%$ for patients treated with diet only. Perhaps, it is due to a very imperfect determination of this group. In the last years, many of these inadequately treated patients started either insulin or oral treatment, and this was the main reason for the decrease of percentage of patients treated with diet only. This is also true for the oral treatment. During 1968-1977, many patients avoided insulin treatment because of their significant inconveniences performing it at that time (serf-sterilization of syringes and needles, lack of self-control at home etc) and preferred to take pils in spite of the poor control. After introduction of disposable syringes/needles and urine/ blood glucose strips, a decrease of usage of oral drugs appeared, reaching $50.8 \%$ of the patients in 1981. After improved attitude and care for diabetes mellitus, the percentage of patients treated with oral drugs began to rise again, not at the expense of insulin, but at the expense of patients inadequately treated with "diet" only (Table 5).

\section{DIABETIC COMPLICATIONS}

The prevalence of major diabetic complications in Bulgaria was estimated for diabetic retinopathy, blindness, nephropathy, amputations and cardiovascular diseases. Diabetic neuropathy was not included in our study because of the great differences in the health institutions in establishing this diagnosis. Usually the early diagnosis of diabetic neuropathy is not possible in the country because most of the doctors are not able to perform quantitative sensory testing of vibration and thermal sensation tests or light touch perception test. While all diabetic patients are compulsory examined once a year by an ophthal-
Table 4. Diabetic patients organization and patients education in Bulgaria before and after Saint-Vincent Declaration

\begin{tabular}{lcc}
\hline Education and lay persons organisation & \multicolumn{2}{c}{ Year } \\
\hline & 1989 & 1994 \\
Centers of patients education (number) & 5 & 12 \\
Books for self-education (titles) & 1 & 6 \\
Specilized newspapers & - & 1 \\
Local lay persons organisations & 23 & 52 \\
Bulgarian Diabetic Association & - & yes \\
Diabetic nurse and educators organisation & - & yes \\
\hline
\end{tabular}

Table 5. Changes in the treatment of diabetes mellitus in Bulgaria

\begin{tabular}{rrccc}
\hline Year* & $\begin{array}{c}\text { Surveyed } \\
\text { patients }\end{array}$ & $\begin{array}{c}\% \\
\text { Diet only }\end{array}$ & $\begin{array}{c}\% \\
\text { Oral drugs }\end{array}$ & $\begin{array}{c}\% \\
\text { Insulin }\end{array}$ \\
\hline 1968 & 31791 & 17.7 & 63.6 & 16.9 \\
1977 & 76001 & 27.1 & 57.3 & 15.4 \\
1981 & 81087 & 32.2 & 50.8 & 16.0 \\
1985 & 72429 & 29.8 & 52.0 & 18.0 \\
1989 & 75306 & 25.9 & 53.5 & 20.6 \\
1990 & 78474 & 23.5 & 53.6 & 22.9 \\
1993 & 144739 & 18.6 & 57.1 & 23.3 \\
\hline
\end{tabular}

* years not mentioned these changes are not determined.

mologist for retinopathy and proteinuria is regularly tested, detailed neurological investigation is not routinely done and diabetic neuropathy is often underestimated. ;: MmKK

Background retinopathy and proliferative retinopathy in diabetic patients are close to the figures in other studies $(2,21)$. It is so, because more than $90 \%$ of Bulgarian diabetic patients have NIDDM (22-24). While the percentage of diabetic retinopathies did not significantly differ in 1990 and in 1994, blindness decreased considerably, from $0.87 \%$ to $0.37 \%$. A dramatic decrease of amputations was established as well. For the same period of time, a reduction of amputations by almost three times was found both for the large amputations (above the ankle) and the total number of amputations (minor plus large ones). A tendency towards lower prevalence of cerebral stroke was found, while myocardial infarction remained unchanged (Table 6). The reported changes are beneficial for diabetic patients and might be a result from the improvement of global diabetes health care in Bulgaria due to the concerted actions of many institutions both on national and international level. 
Table 6. Prevalence rate of diabetic complications in Bulgaria

\begin{tabular}{lrr}
\hline Group of patients & \multicolumn{2}{c}{ Year } \\
\hline & 1990 & 1994 \\
& 76066 & 3226 \\
$\begin{array}{l}\text { Total number of surveyed diabetic } \\
\text { patients }\end{array}$ & $9.6 \%$ & $6.7 \%$ \\
IDDM patients & $90.4 \%$ & $93.3 \%$ \\
NIDDM patients & $21.8 \%$ & $24.8 \%$ \\
Background retinopathy & $3.3 \%$ & $2.9 \%$ \\
Proliferative retinopathy & $0.87 \%$ & $0.38 \%$ \\
Blindness & $5.79 \%$ & $5.45 \%$ \\
Diabetic nephropathy & $1.90 \%$ & $0.64 \%$ \\
Amputations (all cases = minor + large) & $0.13 \%$ & $0.04 \%$ \\
Amputations above the ankle (large) & & \\
Myocardial infarction & $1.49 \%$ & $1.54 \%$ \\
Cerebral stroke & $1.95 \%$ & $1.61 \%$ \\
\hline
\end{tabular}

\section{CONCLUSIONS}

It is obviously that one can not expect an influence of the improved diabetes care on demographic data within a few years since the development of major diabetic complications and eventual fatal outcome may be expected at least 8-10 years after the initial diagnosis of diabetes mellitus. The mortality curve and mortality rate are a reflection of the management of diabetes mellitus during the whole life of diabetic patient. That is why we are expecting improvement of the demographic data and especially of the mortality rate due to diabetes mellitus around the year 2000 .

Many of the recommendations of Saint-Vincent Declaration are already routine practice in Bulgaria. One of the most important recommendation is "to raise awareness in the population and among health care professionals of the present opportunities and the future needs for prevention of the complications of diabetes and of diabetes itself (19). This is also the strategy of diabetologists and health care providers in Bulgaria in realization of all the tasks in the new 1994 version of the National Programme for Diabetes Mellitus adopted by the Ministry of Health.

\section{REFERENCES}

1. Atanasova M, Koprivarova , Savova R, Konstantinova $\mathrm{M}$ et al. Incidence of diabetes mellitus type 1 in Bulgaria children [abstract]. E ASD 28th Annual Meeting, Prague, 8-11 September 1992; 131A
2. Janka HU. Epidemiology and clinical impact of diabetic late complications in NIDIM. In: Mogensen CE, Standl E, editors. Prevention and treatment of diabetic late complications. Walter de Gruyter, Berlin, 1989; 29-40

3. GaranciniMP, Calori G, Ruotolo G, ManaraE, Izzo A, Ebbli E et al. Prevalence of NIDDM and impaired glucose tolerance in Italy: an OGTT-based population study. Diabetologia 1995; 38: 306-313

4. Schoenle EJ, Molinari $L$, Bagot M, Semadeni S, Wiesendanger M. Epidemiology of IDDM in Switzerland. Increasing incidence rate and rural-urban differences in Swiss men born 1948-1972. Diabet Care 1994; 17: 955960

5. lonescu-Tirgoviste C, Paterache E, Cheta D, Farcasiu E, Serafinceanu C, Mincu I. Epidemiology of diabetes in Bucharest. DiabetMed 1994; 11: 413-417

6. Ruwaard D, Hirasing RA, Reeser HM, van Buuren S, Bakker K, Heine RJ et al. Increasing incidence of type I diabetes in The Netherlands. The second nationwide study among children under 20 years of age. Diabet Care 1994; 17: 599-601

7. Cherubini V, Cantarini M, Ravaglia E, Bartolotta E. Incidence of IDDM in the Marche Region, Italy. Diabet Care 1994; 17: 432-435

8. Green A, Gale EA, Patterson CC. Incidence of childhoodonset insulin-dependent diabetes mellitus: the EURODIAB ACE Study. Lancet 1992; 339: 905-909

9. Levy-Marchal C, Czernichow P. Heterogeneity of type 1 diabetes at onset in children: results from the French Incidence Study. DiabetMetab 1993; 19: 296-303

10. Kocova M, Trucco M, Konstantinova M, Dorman JS. A cold spot of IDDM incidence in Europe. Macedonia. Diabet Care 1993; 16: 1236-1240

11. Podar T, LaPorte RE, Tuomilehto J, Shubnikov E.Risk of childhood type 1 diabetes for Russians in Estonia and Siberia. Int JEpidemiol 1993; 22: 262-267

12. Williams DR. Epidemiological and geographic factors in diabetes. Eye 1993; 7: 202-204

13. Jarrett RJ. The epidemiology of diabetes mellitus. In: Pickup JC, Williams G, editors. Textbook of diabetes, vol.1. Blackwell Science, Oxford, 1991; 471-453 
14. Muggeo M, Verlato G, Bonora E, Bressan F et al. The Verona diabetes study: a population-based survey on known diabetes mellitus prevalence and 5-year all-cause mortality. Diabetologia 1995; 38: 318-325

15. Schulz B, Bibergeil H, Rybka J, Koev D. Strategy and structure of diabetes health care in some European socialist countries. In: Krall LP, editor. World book of diabetes in practice. Elsevier Science, Amsterdam, 1988; $367-375$

16. Zimmet P, Dowse G, LaPorte R et al. Epidemiology - its contribution to understanding of etiology, pathogenesis and prevention of diabetes mellitus In: Creutzfeldt W, Lefebre P, editors. Diabetes mellitus: pathophysiology and therapy. Springer-Verlag, Berlin, 1989; 5-26

17. Karvonen M, Tuomilehta J, Libman I, LaPorte R. A review of the recent epidemiological data on the worldwide incidence of type 1 (insulin-dependent) diabetes mellitus. Diabetologia 1993; 36: 883-392

18. Koev D. Prevalence of diabetic complications in Bulgaria according to primary health care system and Diabetes Center registration. G Ital Diabetol 1993; 13: 21-24

19. Krans HMJ, Porta M, Keen H. Diabetes care and research in Europe: the Saint-Vincent Declaration Action Programe, Implementation Documen, WHO, Regional Office for Europe, Copenhagen, 1992

20. Plasser G. Eating patterns in Central and Eastern Europe. In: Lisansky SG, Hall KE, editors. Health, nutrition, low-calorie sweeteners: common themes in a changing Europe, Proceedings, ISA Annual Conference. CPL Press, Newberry UK, 1994; 46-59

21. Walters DP, Gatling W, Houston AC, Mullee MA et al. Mortality in diabetic subjects: an eleven-year follow-up of a community based population. DiabetMed 1994; 11: 968-973

22. Koev D, Daskalova I. Dynamics of the major diabtes complications in Bulgaria in relation with the implementation of Saint-Vincent Declaration [abstract]. Third European Meeting for the Implementation of the St. Vincent Declaration, 29 March -1 April, 1995, Athens, Greece. Harm Metab Res 1995 (Suppl 1); 50A

23. Koev D, Staykov T, Vasilevski N, Hubaveshki S. Epidemiology of diabetes mellitus in Bulgaria, SavrMed 1987; 38: 7-11 (in Bulgarian, Summ in English)
24. KoevD. Epidemiology and national-wide programme for diabtes mellitus in Bulgaria [abstract]. G Ital Diabetol 1989; 9: 300A
Received 5 April 1996

Accepted 27 May 1996

Address for correspondence:

Dr Lidia Koeva

Clinic of Endocrinology

Medical University of Varna

BG-9002 Varna

Bulgaria 